\title{
MEDIUM-TERM MORPHODYNAMIC MODELING OF MIXED MUD AND SAND IN THE TIDAL BASIN JADEBUSEN
}

\author{
Markus Witting ${ }^{1}$, Christof Wehmeyer ${ }^{2}$ and Hanz Dieter Niemeyer ${ }^{1}$
}

\begin{abstract}
A morphodynamic model for the Jadebusen basin based on the current DELFT3D model is established. With morphological information such as qualitative measurements of SPM-concentration (Suspended Particular Matter) and bottom change estimates as well as detailed surveys of a sand pit refilling process the model parameters for cohesive transport (Partheniades 1965) are calibrated. Within a period of 8 month, which is condensed to a representative period of 28 days for the modeling, almost $45 \%$ of the initial pit volume was refilled with mud. Despite the lack of specific field measurements a setup of mud transport parameters can be defined, which allows further investigations of sand pit locations in the Jadebusen basin. On major outcome is that critical erosion shear stresses for mud should be spatially varied in order to account for the different consolidation states of the mud fraction. Furthermore the paper addresses the problem of the initial grain size distribution for graded sediment transport. Wadden flat types are characterized based on aerial observations which build the underlying information for a relocation model run.
\end{abstract}

Keywords: morphodynmic modeling; cohesive sediment transport; initial grain size distribution

\section{AREA OF INVESTIGATION}

The tidal basin Jadebusen is part of the German North Sea coast in the southern German Bight. It consists roughly of one-third of muddy, intertidal flats, one-third of sandy flats and one third of tidal channels. Therefore the sediment composition of the basin is very heterogeneous. For dike reinforcements sand mining projects in the range of $2 * 10^{6} \mathrm{~m}^{3}$ have been carried out in Jadebusen basin and are planned in future. The morphodynamic approach of this study allows estimations on the behaviour and thus detailed planning of these sand-mining projects.

The mean tidal range is $3,8 \mathrm{~m}$ at the inlet of the basin, which can therefore be regarded as tidedominated. Waves enter from the north trough the inlet but the main impact of waves on the sediments results from locally generated waves. The prevailing wind direction is from west-southwest which is also reflected in the spatial distribution of sediment fractions in the Jadebusen basin (Figure 2).

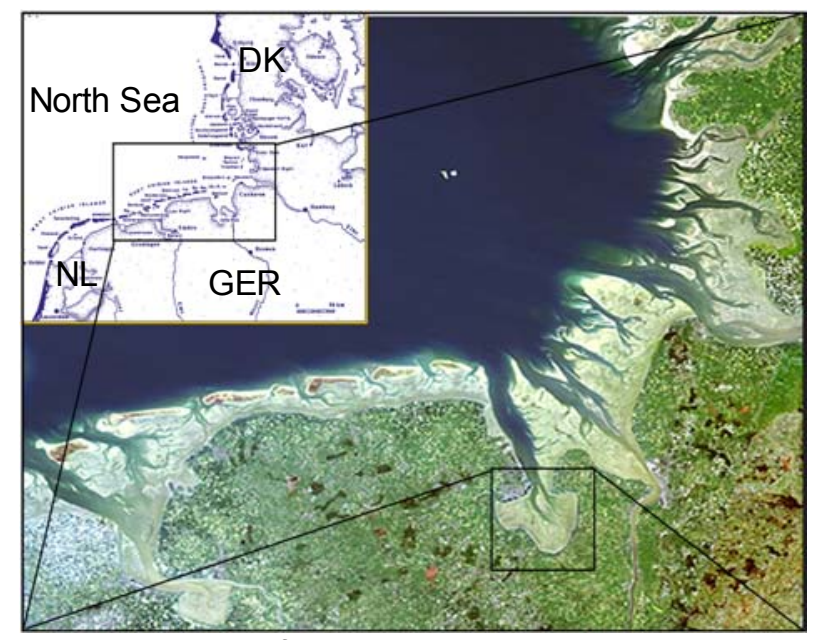

Figure 1. Location of the Jadebusen basin at the german North Sea coast.

\section{Sediment distribution}

Aerial observations of tidal flat types in combination with measured grading curves build the underlying information of the sediment distribution in the Jadebusen (Meyer 1999). The mixed flat type and the mud flat type exhibit a mud-content of $20 \%$ respectively $60 \%$, whereas the dark and light sand flat has no mud content (Table 2).

\footnotetext{
${ }^{1}$ Coastal Research Station of Lower Saxony, An der Mühle 5, 26548 Norderney, Ostfriesland, Germany.

${ }^{2}$ Rambǿll, Willemoesgade 2, DK-6700 Esbjerg, Denmark
} 


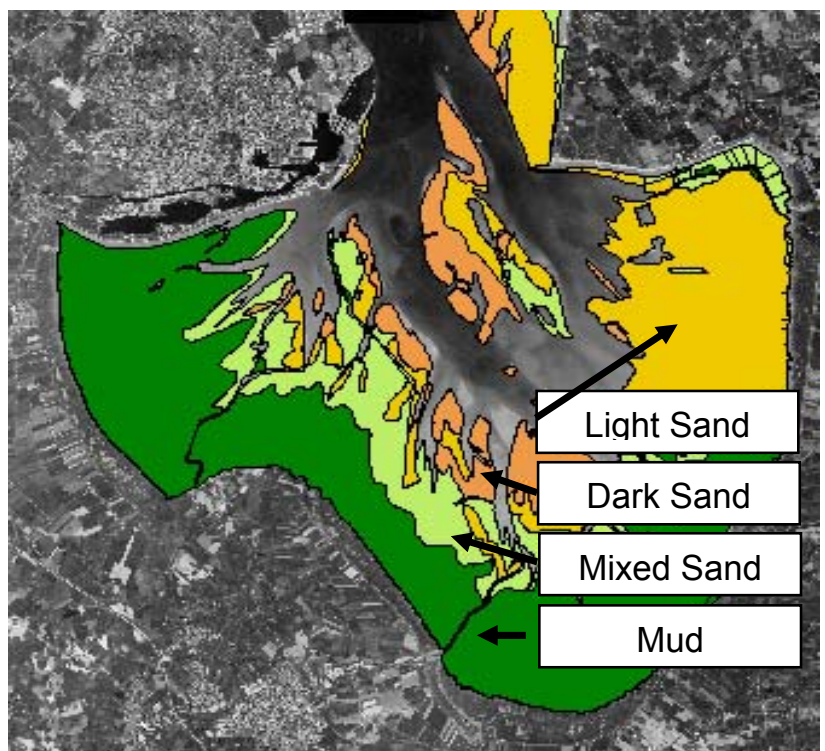

Figure 2 Characterization of wadden flat types from aerial observations.

\section{Available information on morphological processes}

A sand-pit of 1.1 million $\mathrm{m}^{3}$ was excavated in August 1996 in the southwest part of the Jadebusen basin (Figure 5). During the winter season from August 1996 to March 1997, which exhibits frequent winds over $10 \mathrm{~m} / \mathrm{s}$, it was refilled with $493430 \mathrm{~m}^{3}$ which is almost $45 \%$ of its initial volume. Although the fractions of the refilling material were not explicitly measured it can be assumed that it is mostly mud which contributes to the refilling.

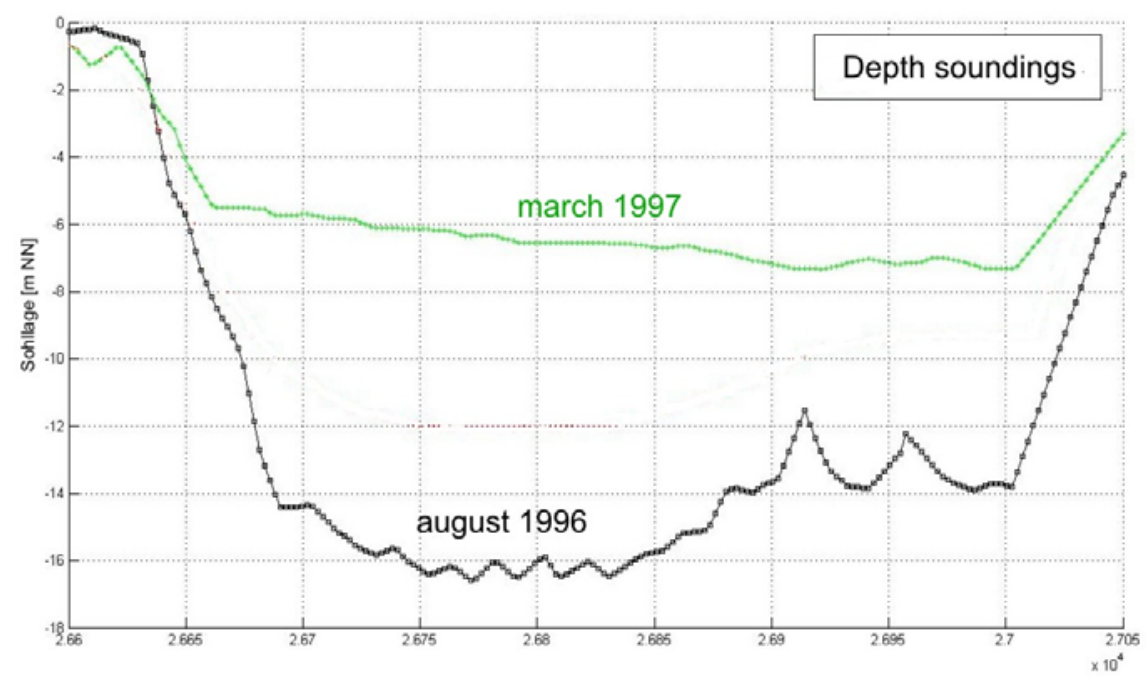

Figure 3. Refilling of sand pit with mud (45\% within 8 month in winter)

SPM-values are measured at the shoulder of a tidal channel (Vareler Tief) in Jadebusen basin. SPM-values correspond to current speeds in the channel and therewith to the tidal neap-spring-cycle (Figure 4). Values at the measuring site are between 100 and $600 \mathrm{mg} / \mathrm{l}$ showing a strong correlation to the tidal situation and to wind events 


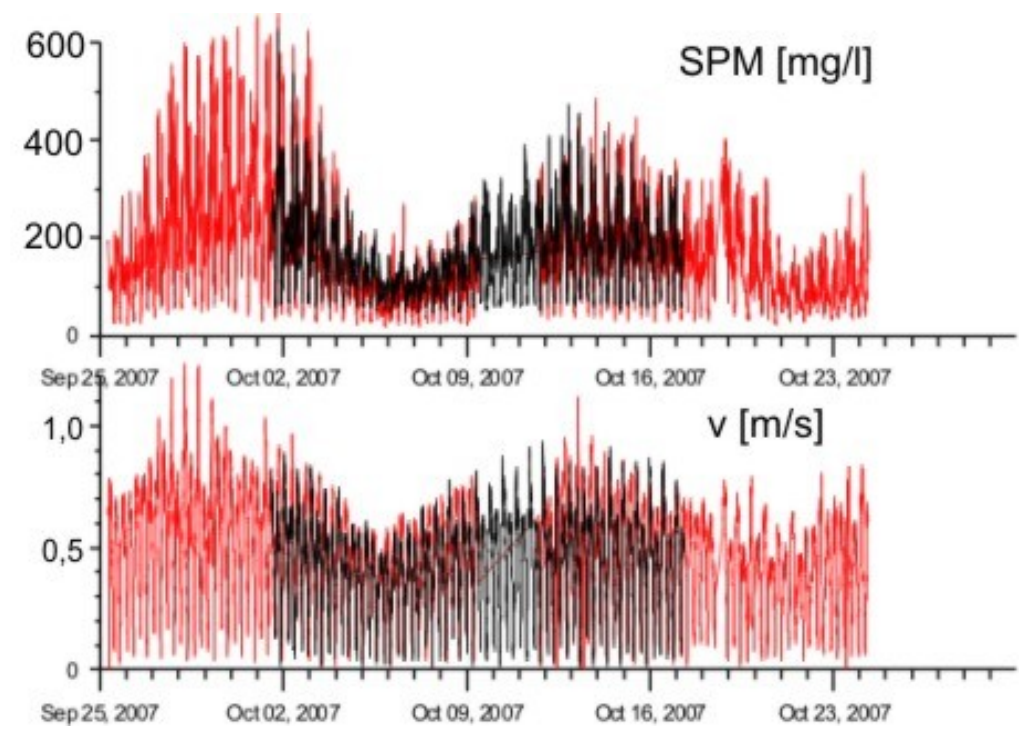

Figure 4. Timeseries of SPM-concentration and current velocity on two stations at Vareler Tief / Jadebusen basin

The general morphodyanmic situation of the Jadebusen basin is investigated in many studies and can be summarized qualitatively: The basin is in a stable dynamic equilibrium determined by the tidal forces. Seasonal changes are related to the probability of wind in combination with local waves. Winter season with exhibits much more and stronger winds lead therefore to erosion on the wadden flats particularly due to the enhanced bottom shear stressed by wave action. Observations indicate a maximal seasonal variability of approximately $30 \mathrm{~cm}$ for the wadden flats. This number is taken as a guideline to limit the allowed erosion of the flats in the morphodynamic modeling.

\section{MODELING ASPECTS}

\section{Delft3D}

The Delft3D-online model suite is applied for this study. The flow is calculated in 2D-horizontal mode using shallow water equations with an algebraic turbulence closure model. A curvilinear grid of $260 \mathrm{x} 331$ grid cells covers the Jadebusen basin with a spatial resolution of $\Delta \mathrm{x} \approx 10 \mathrm{~m}$ in the vicinity of sand pit. An open boundary with water levels (h-values) from a gauge, situated very close to the boundary at the west side of the inlet, is established at the inlet of the Jadebusen basin (Figure 5). The model was hydro-dynamically calibrated with various water level gauges in the south part of the basin. Calibration was done by varying the hydraulic roughness coefficients in the basin. The final Manning values found by the calibration procedure were $\mathrm{n}=0.018 \mathrm{~m}^{-1 / 3} \mathrm{~s}$ for water depth $\geq 15 \mathrm{~m}$ and $\mathrm{n}=0.024$ $\mathrm{m}^{-1 / 3} \mathrm{~s}$ for depth $\leq 2 \mathrm{~m}$ with a linear interpolation in between. Bedforms and their associated roughness were not taken into account, because of the assumed muddy conditions. Experiments in flumes have shown that, if the mud content increases in sandy beds the occurrence of bed forms is suppressed, meaning if the bed is dominated by cohesive sediments, almost no bedforms can be observed (Torfs 1995).

Wave and wind were accounted for by coupling with the waves module of DELFT3D-online with is essentially the SWAN wave model. The time interval for the exchange between current and wave module is set to $\Delta \mathrm{t}_{\mathrm{wave}}=30 \mathrm{~min}$.

Due to the sediment variability of Jadebusen basin 2 sand fractions with $\mathrm{d}=200 \mu \mathrm{m}$ (medium sand) and $100 \mu \mathrm{m}$ (fine sand) and 1 mud fractions with $\mathrm{d}=30 \mu \mathrm{m}$ (see Table 2) are established in the model. The transport of the sand fraction is calculated using the approach by van Rijn (1993). For the predominant mud transport the approach by Partheniades-Krone is used (see below). The model calculates the bottom change due to the transport gradients in every grid cell in a certain time interval $\Delta \mathrm{t}_{\text {morph }}$ which is set to $\Delta \mathrm{t}_{\text {morph }}=30 \mathrm{sec}$. In the calculation every fraction is treated separately and no interaction of the single fraction is taken into account. The dry bed density for mud is also assumed to be constant in time and space. The model uses various sediment layers with different sediment compositions to account for the horizontal and vertical variability of the seabed. The uppermost, thinner layer is the so-called transport layer, here taken to be $0.15 \mathrm{~m}$, which allows the quick adaption of sediment composition due to the fractional transport (see DELFT3D-manual (2006) for details). 


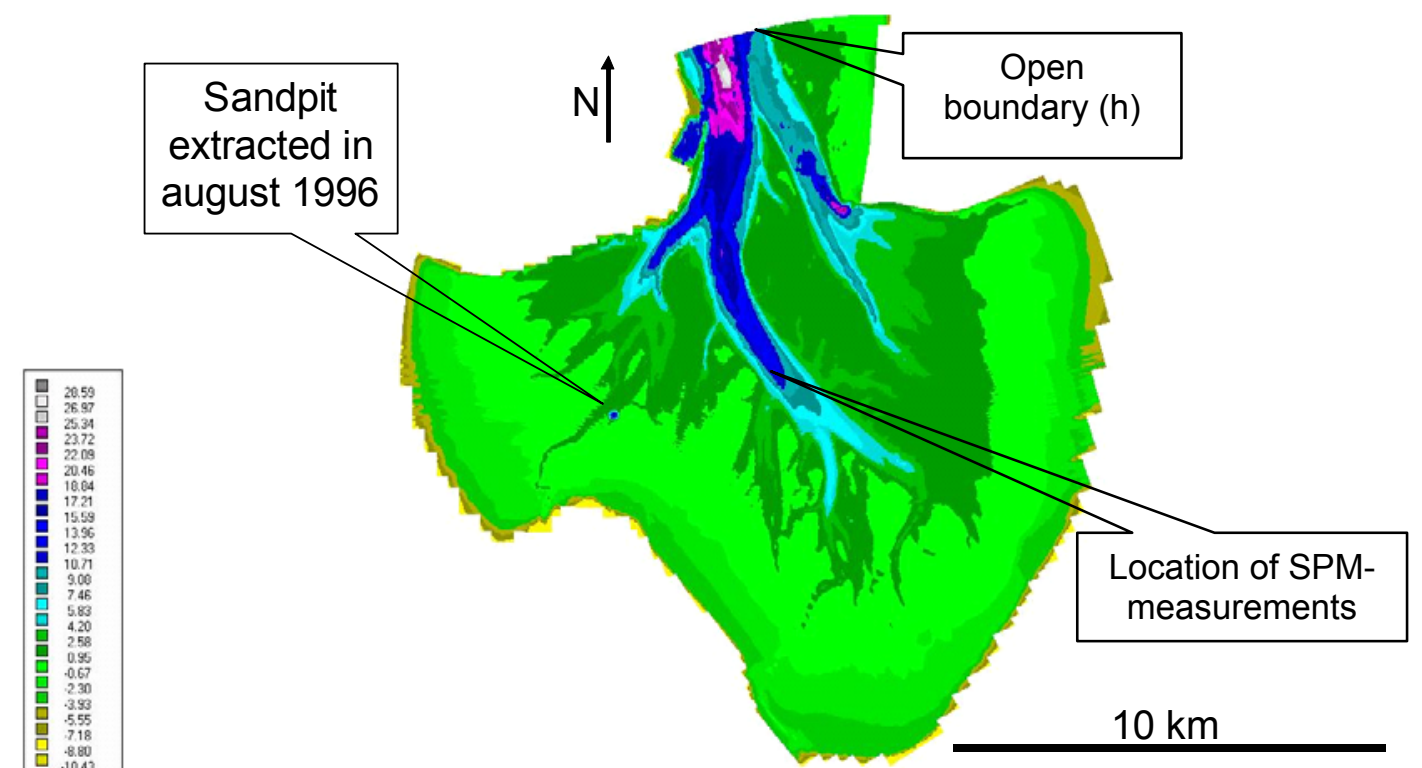

Figure 5. Bathymetry of the model with location of the sandpit, the open water-level boundary and the SPM measurement.

\section{Representative scenario}

Calibration of the model is based on the time period from August 1996 to March 1997 in which the refilling of the sand pit is observed. For minimizing the computational effort, the water level data and the wind data at the measuring gauge in the north of Jadebusen basin (Wilhelmshaven / Alter Vorhafen) have been analysed for the period of August 1996 until March 1997 in order to define a representative period.

So called cost functions have been used to establish a representative period (Boon et al. 2002). In the present case the difference between the period-averaged, i.e. a representative period of 28 days one neap spring cycle - and the long term averaged components, i.e. the total period from August 1996 to March 1997, was calculated. When plotted against time, the cost-functions then give a good impression of the representative quality. A good representative period is obtained when simultaneously occurring minima on all plots can be found. Prior to the following calculations the wind had to be split into its northern and eastern component.

$$
\begin{gathered}
C_{1}=\left(\mu_{\text {nord }, 28}-\mu_{\text {nord }, 1996-7}\right)^{2}+\left(\mu_{\text {east }, 28}-\mu_{\text {east }, 1996-7}\right)^{2} \\
C_{2}=\left(\sigma_{\text {nord }, 28}-\sigma_{\text {nord }, 1996-7}\right)^{2}+\left(\sigma_{\text {east }, 28}-\sigma_{\text {east }, 1996-7}\right)^{2} \\
C_{3}=C_{1} / \sigma_{C 1}+C_{2} / \sigma_{C 2}
\end{gathered}
$$



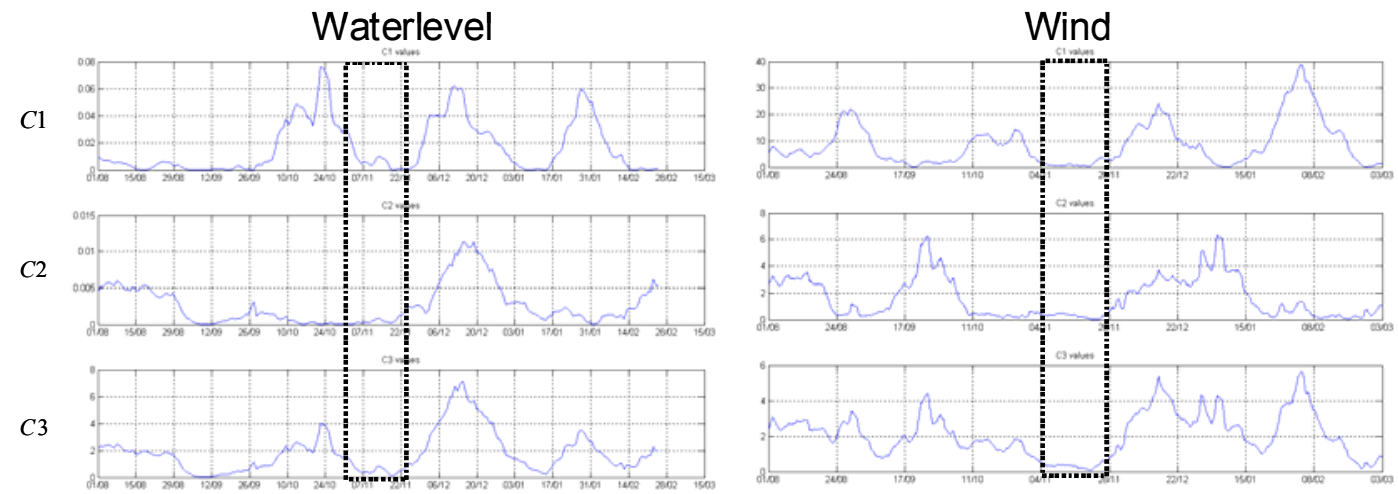

Figure 6. Representative spring-neap cycle (28 days) out of the period august 1996 - march 1997

Six cost functions have been plotted against the total period (figure 6) and the representative period of 28 days was defined by visual inspection. The latter was selected as: 01-Nov-96 until 29Nov-96. In order to account for the whole period in terms of seabed changes a morphological factor morfac $=8$ is applied on the calculated seabed changes.

\section{Mud properties}

Since the sand-pit is situated in a mudflat area, mud transport is dominant transport in the study area. The behaviour of older mud differs significantly from the biologic active top layer, concerning its plasticity and its cohesiveness. Similarly as freshly deposited mud differs in its behaviour from already consolidated or biological active mud. Several bed properties influence the erosive behaviour; physical parameters as well as biological. Modeling of natural beds requires also consideration of timedepended structural impacts, e.g. biological growth, chemical reactions or compaction, which all contribute to the adhesive forces of the mud. The used implementation of DELFT3D works with the following approach:

The mud flux from the bed into the water is given by:

$$
F_{m}=E_{m}-D_{m}
$$

With $E_{m}, D_{m}$ being the erosion and deposition rate of mud at the bed respectively. The well known Partheniades and Krone formulations (Partheniades, 1965) describe the erosion of mud as:

$$
E_{m}=\operatorname{Eropar}\left[\frac{\tau_{b}}{\tau_{\text {crit,eros }}}-1\right] H\left[\frac{\tau_{b}}{\tau_{\text {crit,eros }}}-1\right]
$$

Where Eropar is the empirical erosion parameter and $\mathrm{H}$ is a so called Heavi-side function with a value of 1 if larger than 0 , and of 0 if lesser. The formula describing the deposition of mud reads:

$$
D_{m}=-w_{m} c_{m}\left[1-\frac{\tau_{b}}{\tau_{\text {crit,depos }}}\right] H\left[1-\frac{\tau_{b}}{\tau_{\text {crit,depos }}}\right]
$$

$\tau_{b}, \tau_{\text {crit, }, \text { ros }} \tau_{\text {cri,depos. }}$ are the shear stresses acting, the critical stress for erosion and the critical stress for deposition, respectively. $\mathrm{W}_{\mathrm{m}}$ and $\mathrm{c}_{\mathrm{m}}$ are the falling velocity and concentration of mud respectively. Partheniades (1965) stated that the deposition and erosion of mud act independently from each other. The critical shear stress for deposition is smaller than the critical shear stress for erosion, resulting in the existence of a bandwidth of shear, within neither erosion nor deposition of mud occurs.

Winterwerp \& van Kesteren (2004) concluded that both phenomena occur simultaneously and determine therefore the deposition rate as a function of the sediment flux at the bed by the product of the falling velocity and the concentration of the sediment at the bed: 


$$
D=w_{s, b} c_{b}
$$

By some researchers the possibility of a changing $\tau_{\text {crit,eros }}$ is discussed, leading to varying erosion rates in naturally deposited beds. The latter reduce with time, assuming steady erosive conditions (Partheniades 1980). Samford \& Maa (2001) also described this behaviour by stating that $\tau_{\text {crit,eros }}$ increases proportionally with depth.

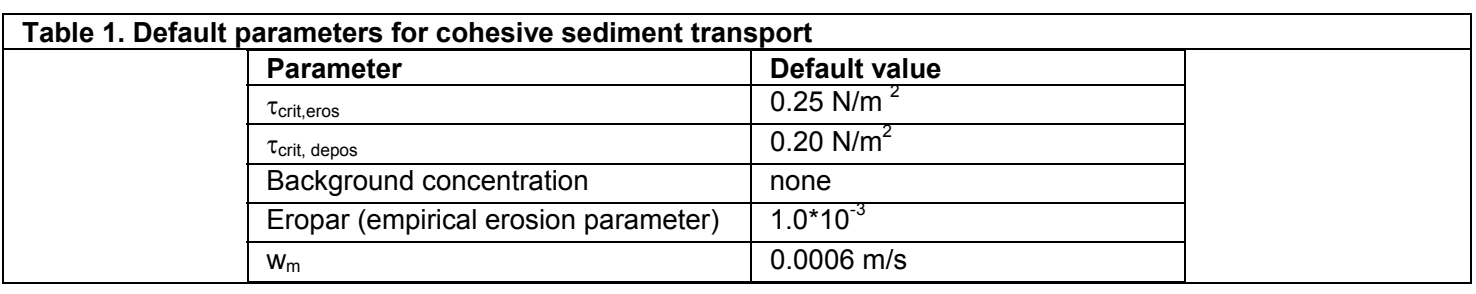

The shown equations are considered only valid for cohesive mud beds. In case of sand/mud mixtures the bed behaviour changes significantly. In spite of that, Torfs (1996) stated that the erosive behaviour of such beds can be described by the Partheniades formula satisfactorily.

Mud in sand beds, as occurring in the mixed sand flats, changes the erosion characteristics, such that the erosion resistance increases, due to a decreasing water infiltration capability. The sand particles are not any longer in direct contact with each other, the empty spaces are filled with mud, the movement of the sand particles is decreased and the pivoting angle is too large and hinders the initiation of motion (Panagiotopoulos 1997). Mitchener \& Torf (1996) found a change from cohesionless to cohesive nature of the sediment erodibility at a mud content of $3 \%$ to $15 \%$, which coincides to the findings of van Ledden (2001). Hence both fractions can not be treated independently, which is in contrast to the actual model implementation of DELFT3D. V. Ledden also stated that the cohesiveness of natural beds not only increases with increasing clay content, also decreasing water content contributes to it, which is similar to the different erosive behaviour due to differences between consolidated and freshly deposited mud. Sand in mud beds as occurring in the muddy sand flats (Figure 2) increases the critical shear stress for erosion, eventually due to the improved drainage, resulting in more compaction.

\section{DETERMINATION OF INITIAL GRAIN SIZE DISTRIBUTION}

The approach of an initial grain relocation run (Hirschhäuser 1998) differs from the standard approach to generate the sediment distribution in an area of interest, using grab sampler, several drilled sediment cores, sieving, etc, and afterwards modelling the spatial distribution, based on the measured values. Often cores and high resolution measurements of areas with high spatial dimensions are absent; hence estimations need to be done. In this case a grain relocation run is a helpful tool (Witting et al. 2004, Escobar et al. 2006). The sediments and their spatially patched occurrence are given as best known and exposed to a number of tidal cycles. This will sort the grains in the model area. A stable situation of the relocation is desired, i.e. a long term equilibrium situation, not any longer influenced by single events such as the actual tidal cycle.

Although an observed sediment distribution was available, it is reasonable to state that these measurements contain errors, and represent only an average, non-synoptic picture. It could not be assumed that the latter is as accurate as the complete natural variability; the accuracy was limited to the temporal limitations of the observation time and the measurement techniques, which was mainly visual interpretation of flat characteristics based on aerial photos. Hence it was seen as a guideline and used as a basis for the relocation model run.

The aim was to achieve a kind of dynamic equilibrium situation, after which no severe morphological changes happen anymore and the intersection between the different deposits patches have been smoothed. Though, it was still desired, that the equilibrium situation should be close to the observed sediment distribution, which is the aerial observation and wadden flat type classification (Figure 2). For the spatial modelling of the sediment patches, three fractions have been previously defined: 1 cohesive and 2 non-cohesive (see above). These were used to set up the sediment composition for the wadden flat types (Table 2). 
Table 2 Composition of sediment fractions for defined waddenl flat types

\begin{tabular}{|c|c|c|c|c|c|}
\hline $\begin{array}{c}\text { Classification of } \\
\text { tidal flat }\end{array}$ & $\begin{array}{c}\text { measured } \\
\mathbf{d}_{50}[\mu \mathrm{m}]\end{array}$ & $\begin{array}{c}\text { fraction } \\
\text { medium sand } \\
(\mathbf{m S}) \\
\mathbf{2 0 0} \mu \mathbf{m}\end{array}$ & $\begin{array}{c}\text { fraction fine } \\
\text { sand } \\
(\mathbf{f S}) \\
\mathbf{1 0 0} \boldsymbol{\mu m}\end{array}$ & $\begin{array}{c}\text { fraction } \\
\text { cohesive mud } \\
\text { (mud) } \\
\mathbf{3 0} \mu \mathrm{m}\end{array}$ & $\begin{array}{c}\text { modelled } \mathbf{d}_{50} \\
{[\mu \mathrm{m}]}\end{array}$ \\
\hline Channels & - & $80 \%$ & $20 \%$ & $0 \%$ & $\mathbf{1 8 0}$ \\
\hline Light sand flat & $\mathbf{1 4 0 - 1 3 4}$ & $40 \%$ & $60 \%$ & $0 \%$ & 140 \\
\hline Dark sand flat & $\mathbf{1 2 8 - 1 1 4}$ & $20 \%$ & $80 \%$ & $0 \%$ & $\mathbf{1 2 0}$ \\
\hline Mixed flat & $\mathbf{1 0 0 - 9 5}$ & $10 \%$ & $70 \%$ & $20 \%$ & $\mathbf{9 6}$ \\
\hline Mud flat & $\mathbf{7 1 - 6 2}$ & $5 \%$ & $35 \%$ & $60 \%$ & $\mathbf{6 3}$ \\
\hline
\end{tabular}

During the relocation procedure, the three fractions in each layer adjusted to the actual hydrodynamic conditions. The resulting fragments of each sediment fraction could be investigated and have been given in parts of one. As a check the summation of the three fraction fragments yielded 1 , which is equivalent to $100 \%$, per sediment layer.

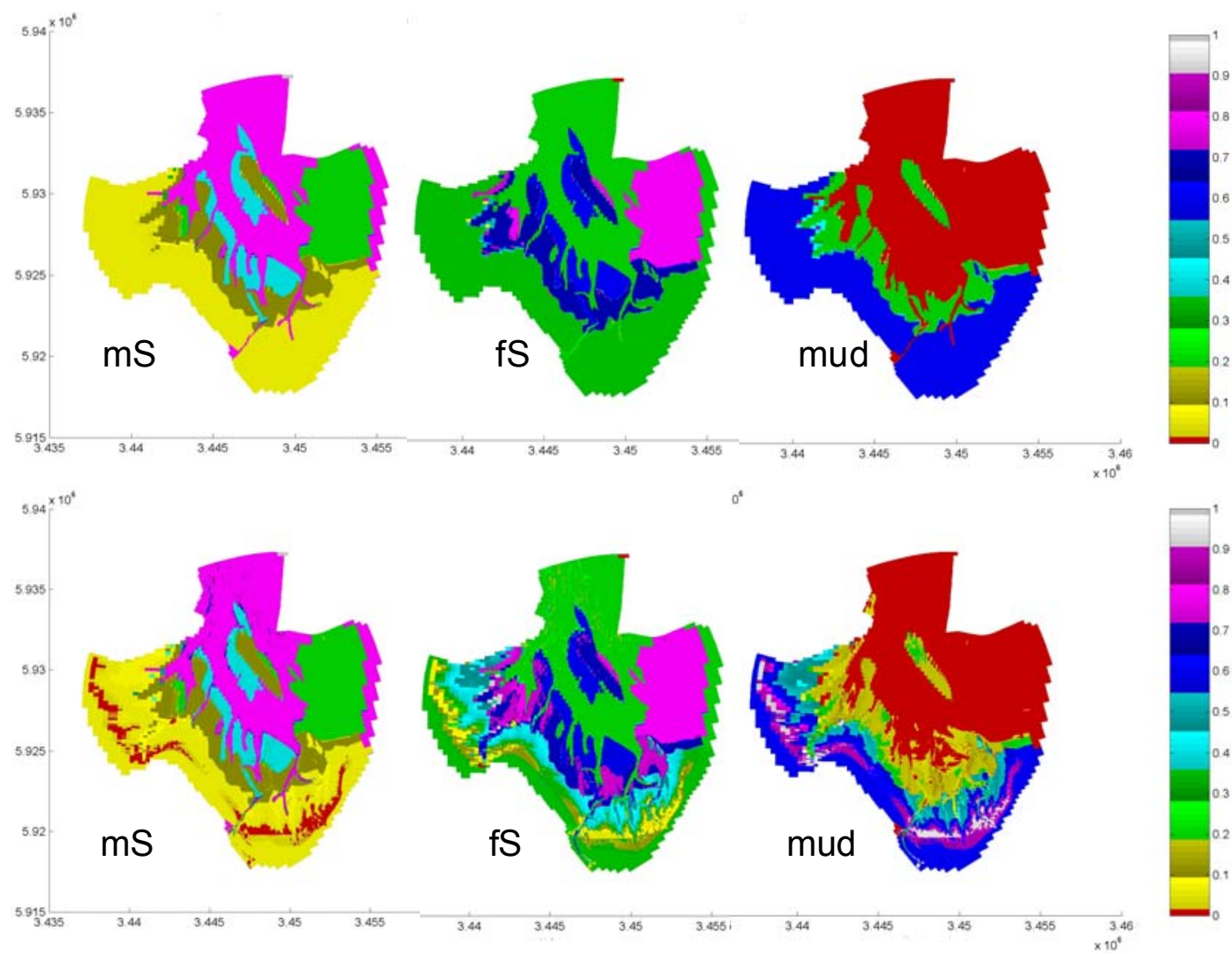

Figure 7. Content of medium sand (left), fine sand (middle) and mud (right) in the first sediment layer at the start of the relocation model run (upper), and at the end of the relocation run (lower).

The length of the redistribution model run was taken to 28 days with tidal forcing only. During relocation 12 layers developed (as previously defined): One transport layer, 10 under layer and one base layer. The 3 most upper ones have been further investigated towards their possible use as initial grain size distribution. To get the most stable situation within the relocation run the simulation stopped at the highest velocities (before high water in the flood phase), therewith the bed was sorted in the "roughest condition" (Hirschhäuser 1998). The transport layer was neglected, because it reacted instantly to the hydraulic forces and was therewith not capable to achieve a stable sediment mixture. The seabed was not allowed to change. The stopping criteria for redistribution run were: 
- Decaying changes of sediment fractions the transport sediment layer $(0.15 \mathrm{~m})$,

- Smooth spatial transitions for all sediment fractions.

Because the results coincided with the measurements in large areas the quality of the new distribution was seen as highly feasible. For the last 10 days the second and the second sediment layer showed stable sediment mixtures and the desired similarities to the initial grain distribution as well as smoothed transitions between the various fraction patches. The implementation of a second layer underneath the top layer, with also spatial varying sediment distribution, should provide a more accurate picture of the natural occurrences of the grain patches, not only in the horizontal, but also in the vertical.
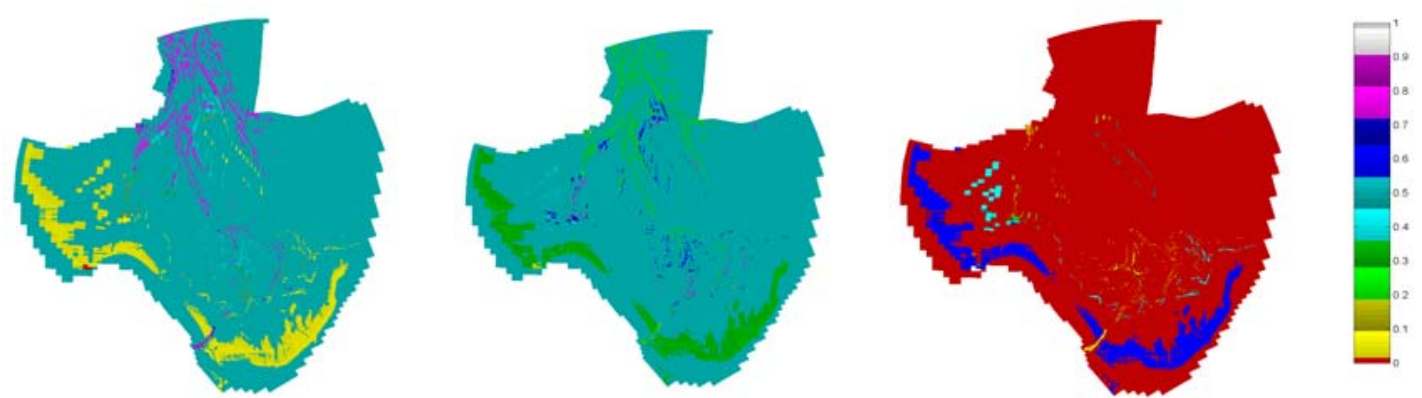

Figure 8. Content of medium sand (left), fine sand (middle) and mud (right) in the second sediment layer at the end of the relocation run.

\section{SENSITIVITY ANALYSIS OF MUD TRANSPORT PARAMETERS}

Mud transport parameters have been changed on a wide range during the sensitivity analysis. The focus of these calculations was to identify parameters, which significantly influence the deposition and backfill of the sand pit (Figure 3), which influence the concentration of SPM (Figure 4) at a measuring point in the Jadebusen basin and which effects the deposition in the channels and the erosion of the tidal flats. The sensitivity of various model parameters is analysed on referential computational nods in the channels, on the flats an in the sand-pit itself. The following figures show the average of the referential values.
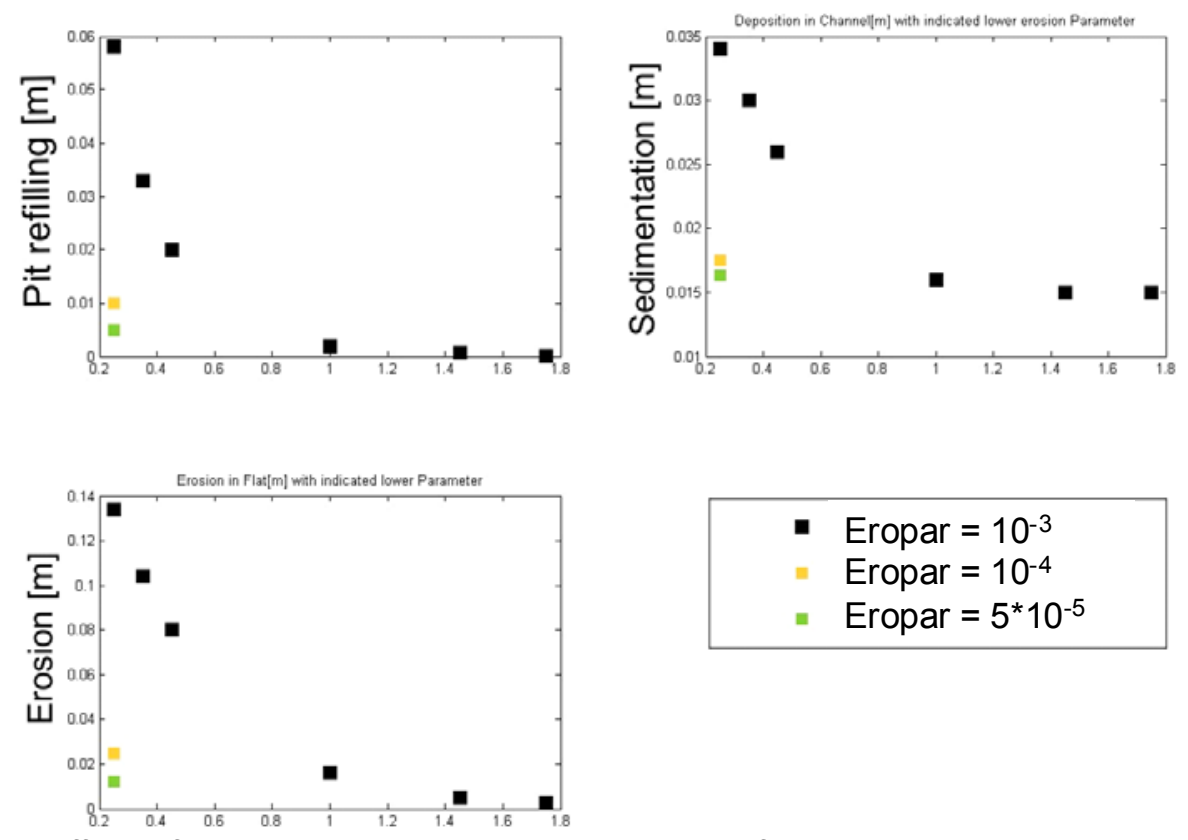

- Eropar $=10^{-3}$

- Eropar $=10^{-4}$

- Eropar $=5^{*} 10^{-5}$

Figure 9. Effects of varying $\tau_{\text {crit,eros }}$ and Eropar values on pit refilling, sedimentation in channels and erosion on flats 
The critical erosion shear stresses $\tau_{\text {criteros }}$ has a distinct effect on all seabed changes. Increasing $\tau_{\text {criteros }}$ limits the erosion of the tidal flats and the backfill of the sand pit. The deposition in the channel shows a similar correlation, which gives reason for the assumption that the material from the tidal flat acts as a source for the deposition processes. A decreasing erosion parameter Eropar limits the erosion flux and the associated sedimentation (Figure 9).

The high erosion parameter Eropar is responsible for a higher backfill due to the higher erosion on the flats. The same accounts for the values of the measurement points in the tidal channel. Still the higher erosion parameter results in higher sedimentation, which is not overcome by the low $\tau_{\text {crit,eros }}$ $\left(0.25 \mathrm{~N} / \mathrm{m}^{3}\right)$. To keep the sedimentation low in the channels, $\tau_{\text {crit,eros }}-$ in this case resuspension - needs to be quite low, which would on the other hand increase the erosion on the tidal flats. A spatially varying critical shear stress for erosion was hence recommended, which reflects the history of consolidation of the material according to the acting forces. Hence the critical shear stress should be lower in the channels, because due to tidal currents only little consolidation takes place, whereas on the tidal flats accumulated material can consolidate yielding a higher erosion resistance.
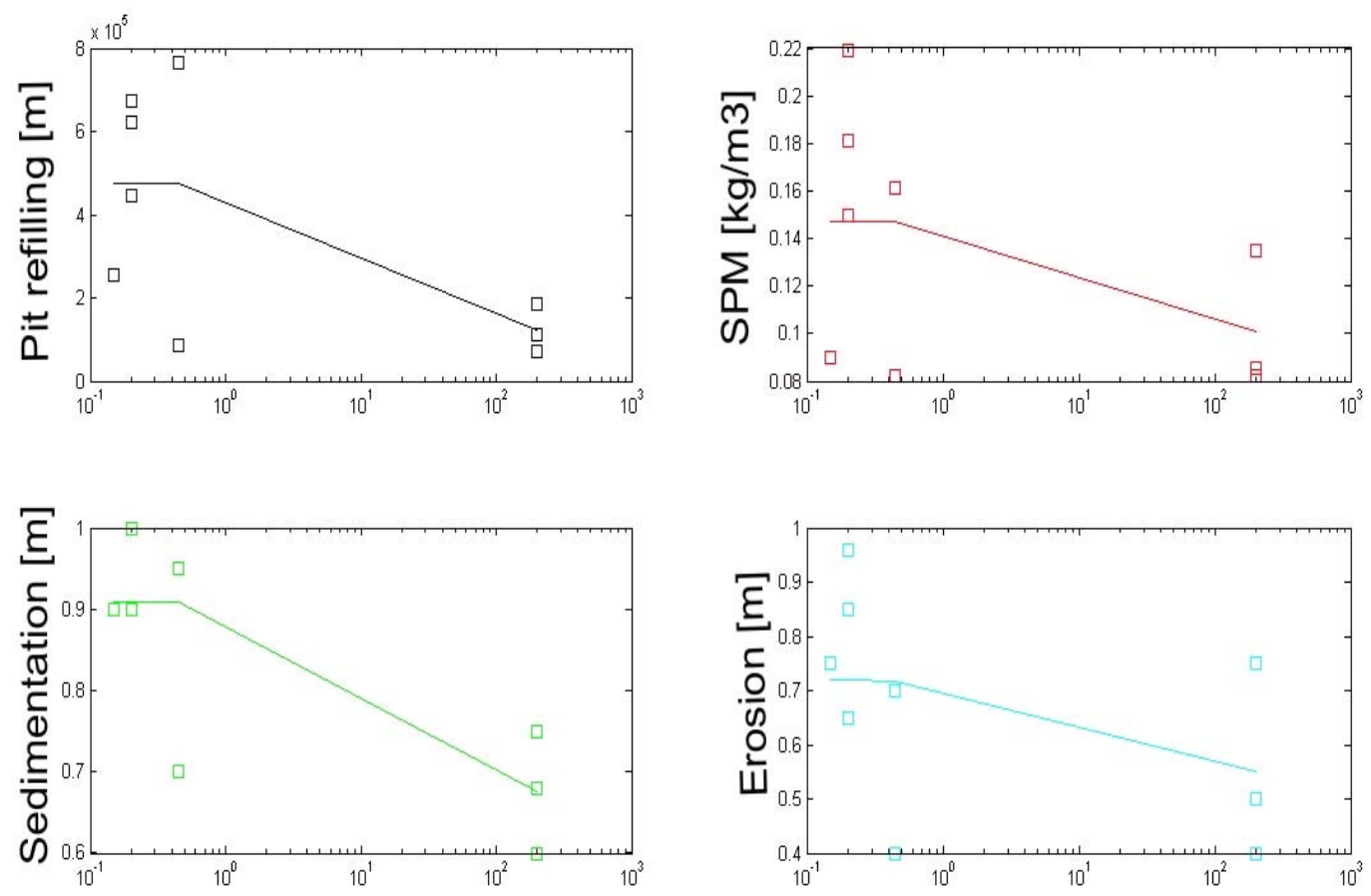

Figure 10. Effects of varying $\tau_{\text {crit,depos }}$ on pit refilling, SPM-concentration, sedimentation in channels and erosion on flats

The parameter $\tau_{\text {crit,depos }}$ shows no clear effect on the observed processes. There is a tendency that higher values reduce the bottom changes in general, obviously due to the fact that less sediment is deposited and more sediment remains in the water column. 

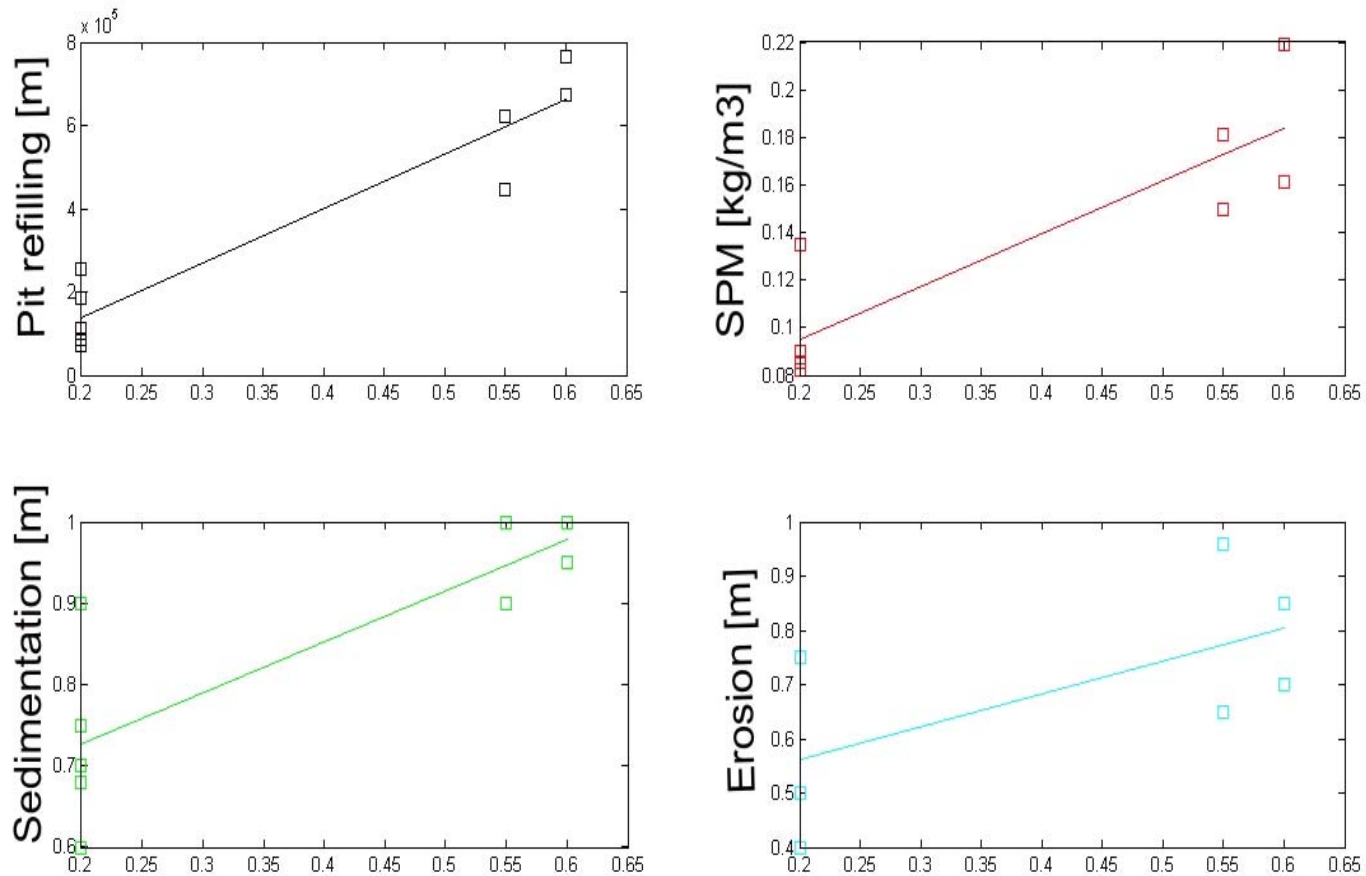

Figure 11. Effects of varying sinking velocity $w_{m}$ on pit refilling, SPM-concentration, sedimentation in channels and erosion on flats.

In contrast to $\tau_{\text {crit,depos }}$, the sinking velocity of the mud fraction has an unambiguous and strong effect on the bottom changes and on the SPM concentration. The higher the sinking velocity is, the greater the bottom changes and the SPM-concentration get (Figure 11).

Combining higher background concentrations on the inflow boundary with higher sinking velocities enhances the deposition in both the channels and the sand pit to an unrealistic extend. A smaller falling velocity leads to the desired SPM-concentration in the range of $100-600 \mathrm{mg} / \mathrm{l}$, but still produces an acceptable refilling volume in the sand pit. Limiting the erosion on the flats by applying a higher $\tau_{\text {criteros }}$-value on the wadden flats is essential to get a realistic seasonal variability of seabed changes in the order of $30 \mathrm{~cm}$. No consolidation of mud can be observed in the channels, hence much lower $\tau_{\text {crit,eros}}$-values should applied there. The following parameter set is found in the course of the 50 sensitivity model runs, which reproduces best the morphological information of the Jadebusen basin:

Table 3. Chosen parameter values for cohesive sediment transport after calibration

\begin{tabular}{|l|l|}
\hline Parameter & Chosen value \\
\hline$\tau_{\text {crit,eros }}$ & $0.14 \mathrm{~N} / \mathrm{m}^{2}$ (flats) $/ 0.48 \mathrm{~N} / \mathrm{m}^{2}$ (channels) \\
\hline$\tau_{\text {crit, depos }}$ & $0.20 \mathrm{~N} / \mathrm{m}^{2}$ \\
\hline Background concentration & $0.45 \mathrm{~kg} / \mathrm{m}^{3}$ \\
\hline Eropar (empirical erosion parameter) & $3.8^{*} 10^{-3}$ \\
\hline $\mathrm{w}_{\mathrm{m}}$ & $0.0002 \mathrm{~m} / \mathrm{s}$ \\
\hline
\end{tabular}

\section{MODEL RESULTS}

Main goal of the sensitivity analysis of mud transport parameters was to calibrate the model on the processes responsible for the refilling of the sand pit. Therefore model setup parameters are preferred which support the quick refilling process observed between August 1996 and March 1997. Values for SPM-concentration of average $300 \mathrm{mg} / \mathrm{l}$ and erosion of tidal flats in the order of $30 \mathrm{~cm}$ are regarded as guidelines.

The modeled bottom changes range within the desired limits. The focused limit of $30 \mathrm{~cm}$ is only slightly exceeded on the southeasterly wadden flats and in the port of Wilhelmshaven, which is known to trap lots of fines (Figure 12). Generally sedimentation takes place in channels, whereas mudflats are eroded. 

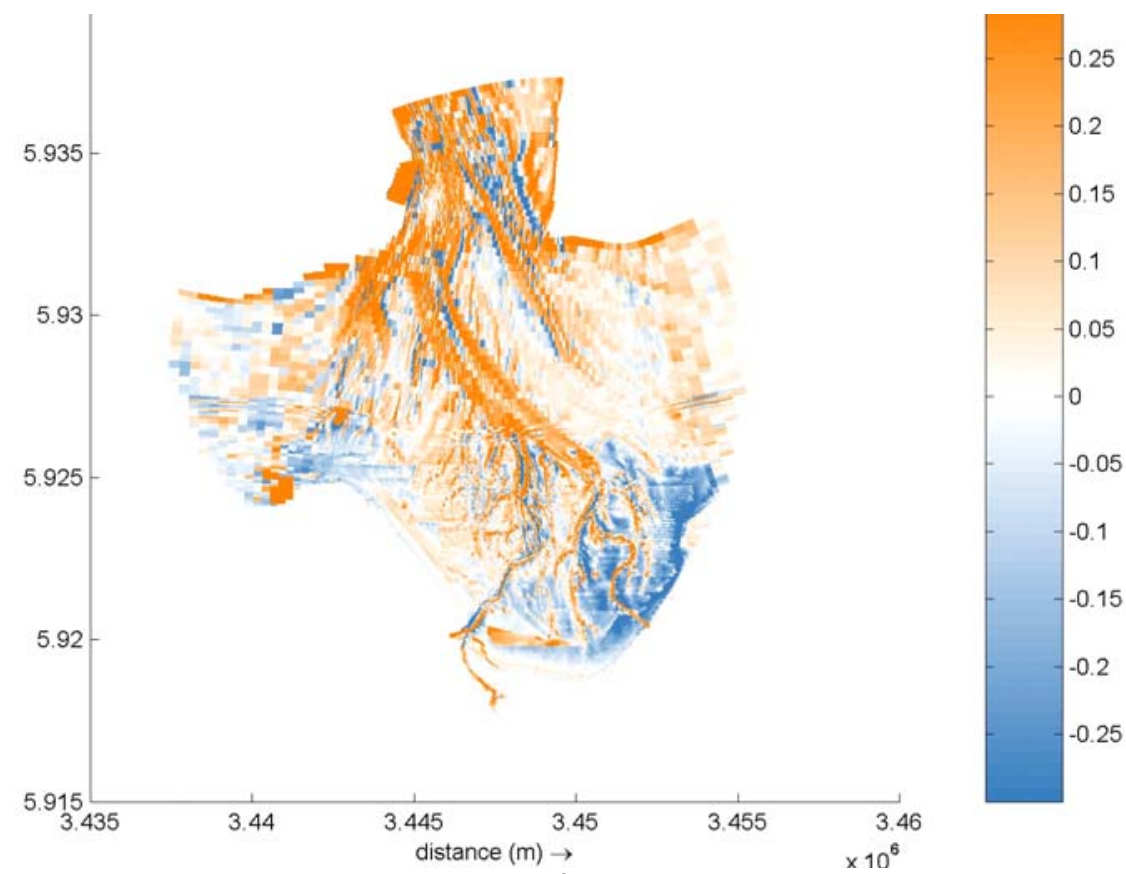

\section{Sedimentation}

Erosion

Figure 12. Model result: Bottom changes from August 1996 to March 1997

The modeled SPM-concentration are in the range and variability of the measurements. Values range in a bandwidth from $100 \mathrm{mg} / \mathrm{l}-400 \mathrm{mg} / \mathrm{l}$ with average values from 250-300 mg/l. During stronger winds from the north-northwesterly directions concentrations pick up to higher values. This behaviour corresponds to the qualitatively observed ones in the Jadebusen basin.

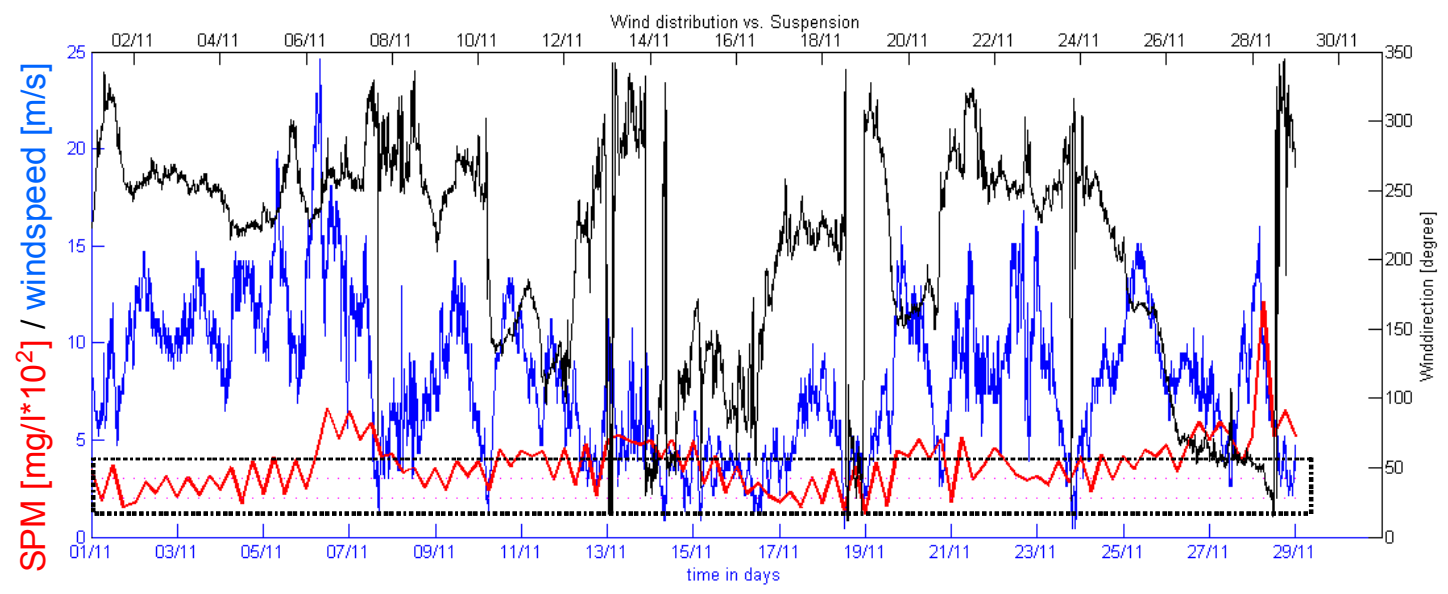

Figure 13. Time series of modeled SPM (mud) concentration and wind speed and direction

The observed gain of mud volume in the sand pit is very similar in model and nature: The modelled refill volume adds up to $444280 \mathrm{~m}^{3}$ whereas the measured refill volume is $493430 \mathrm{~m}^{3}$. The excellent agreement of seabed evolution is illustrated by the means of two cross section of the sand pit (Figure 14 and Figure 15). The measured seabed is only slightly above the modelled one. 


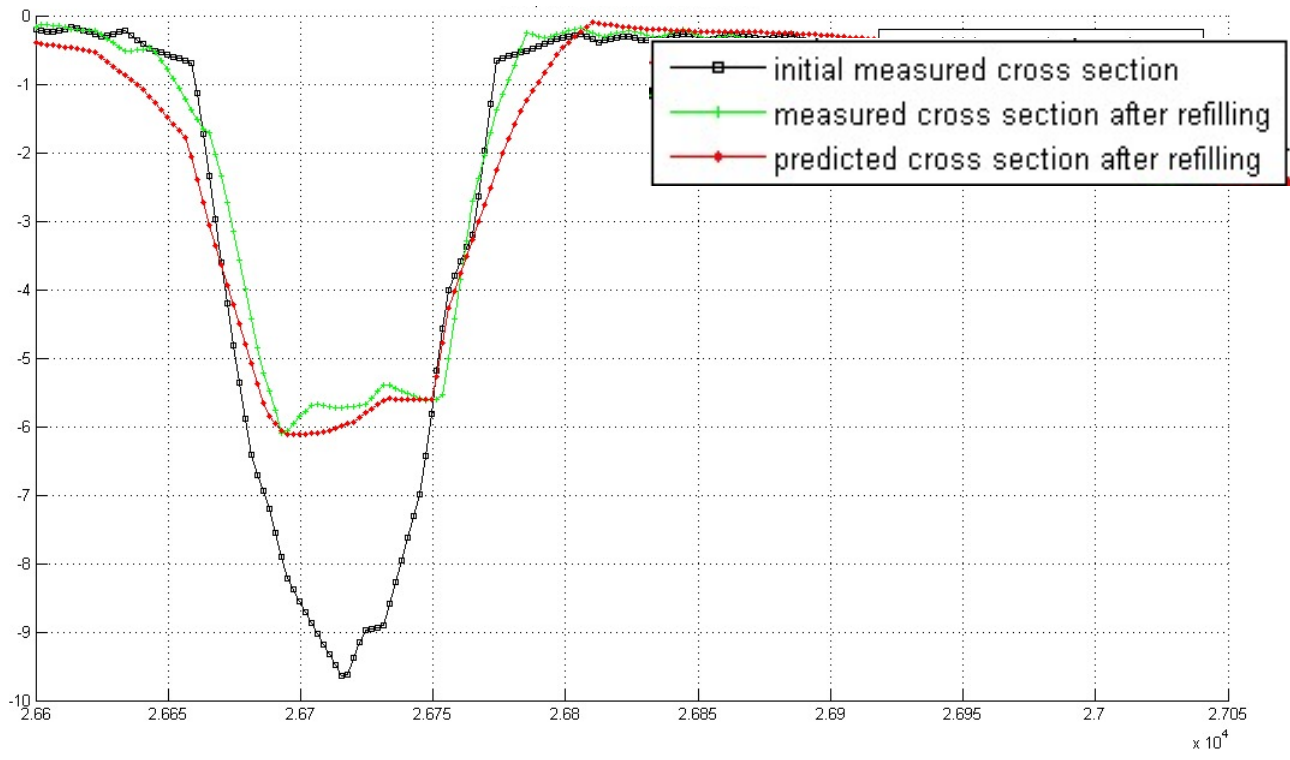

Figure 14. Cross-section before and after refilling process - western part of the pit

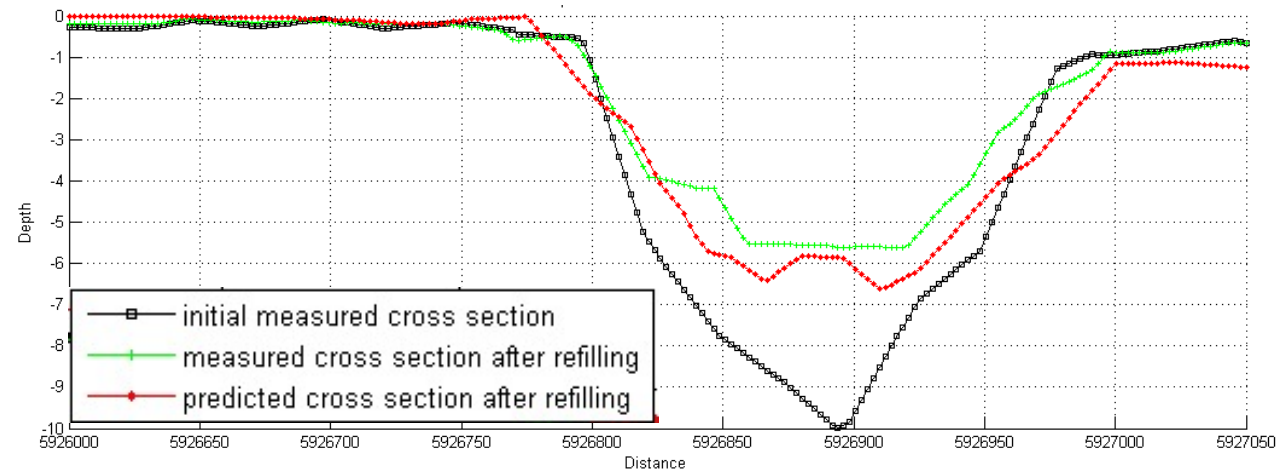

Figure 15. Cross-section before and after refilling process - eastern part of the pit

\section{CONCLUSIONS}

A sandpit refilling process of 8 month can be modelled with the DELFT3D-online model in the Jadebusen basin using 2 sand and 1 mud fraction. The parameters for mud transport based on the Partheniades-Krone approach are calibrated with the available morphological information of the area of investigation, namely the refilling process of a sand pit, measured SPM values and a guideline limiting the seasonal bottom changes. The main finding is that the critical bottom shear stress for erosion should be adapted to the spatially varying states of mud consolidations, namely the differentiation of channels and flats.

Modeling is carried out with condensed input data based on a representative time period of 1 month. Representation is achieved regarding the average and the standard-deviation of wind and waterlevel measurements in the desired time period of 8 month. Thus a morphological factor of 8 is applied to account for the seabed changes.

An initial grain size distribution is defined by a rough estimate of the location of wadden flat types in Jadebusen basin in combination with a relocation model run. This leads to a smooth spatial transition of the sediment composition in the formerly linearly defined boundaries of the wadden flat types. Essentially this procedure establishes a sound initial grain size distribution where no erroneous initial bed level changes occur in the modeling.

By using the available morphological information of the Jadebusen basin an engineer tool is established in this study which can be utilized for future investigations of the effect and the fate of sand-mining projects. 


\section{ACKNOWLEDGMENTS}

This work is carried out in the framework of an investigation mandated by the II. Oldenburgischer Deichband, Germany.

\section{REFERENCES}

Boon, J. \& Kerkamp, H. \& Dardengo, L. 2002. Alternative Dumping Sites in the Ems-Dollard Estuary, Model Study, WL|Delft Hydraulics Z3328

Dankers. 2002. The Behavior of fines released due to dredging. A literature review. TU DELFT, Hydraulic Engineering Section, Faculty of Civil Engineering and Geosciences, Delft University of Technology. Delft.

DELFT3D MANUAL. 2006. WL|Delft Hydraulics: Delft3d-Flow. User-Manual, version 3.10. WL|Delft Hydraulics. Delft.

Escobar, C.A. \& Mayerle R. 2006. Procedures for improving the prediction of equilibrium grain sizes, bed forms and roughness in tidally-dominated Areas. Proc. Of 30th Int. Conf. On Coast. Engr., San Diego.

Hirschhäuser, T., Mewis, P., Zanke, U. 1998. Determination of initial particle size distribution for morphodynamic modeling in tidal area, Proc. of 3. Int. Conference on Hydrosc. and Engr., Cottbus

Meyer, C. \& Ragutzki, G. 1999. KFKI Forschungsvorhaben Sedimentverteilung als Indikator für morphodynamische Prozesse, MTK 0591, Dienstbericht Forschungsstelle Küste 21/1999. Niedersächsisches Landesamt für Ökologie (in german), Internal Report

Panagiotopoulos, I. \& Voulgaris, G. \& Collins, M.B. 1997. The influence of clay on the threshold of movement of fine sandy beds. Coastal Engineering, 32: 19-43. In Dankers (2002).

Partheniades, E. 1965. Erosion and deposition of cohesive soils, Journal of the Hydraulic Division, Vol. 91, No.1, S.105-139.

Partheniades, E. 1980. Cohesive sediment transport mechanics and estuarine sedimentation. In Dankers (2002).

Sandford, L.P. \& Maa J.P.-Y. 2001. A unified erosion formulation for fine sediments. Marine Geology, 179, 9-23. In Dankers (2002).

Torfs, H. \& Mitchener, H. 1995. Erosion of sand/mud mixtures. Coastal Engineering, 29: 1-25. In Dankers (2002).

Torfs, H. \& Mitchener, H. \& Hysentruyt, H. \& Toorman, E. 1996. Settling and Consolidation of sand/mud mixtures. Coastal Engineering, 29: 27-45.

Van Ledden 2001. Modelling of sand-mud mixtures, Part II: A process-based sand-mud model. Z2840 - collaboration between "Zand-slib" project at WL|Delft Hydraulics and Ph.D. project "Large scale segregation in estuaries and tidal lagoons" at Delft University of Technology. Delft

Van Rijn, L.C. 1993. Principles of Sediment Transport in Rivers, Estuaries and Coastal Seas. Aqua Publications. Delft.

Winterwerp, J.C. \& van Kesteren, G.M., 2004. Introduction to the physics of cohesive sediment in the marine environment, Developments in Sedimentology 56, Elsevier

Witting, M., Zanke, U., Mewis, P., 2004. Multiple grain size morphodynamic modeling at Teigmouth (UK), Proc. 5th Int. Conference on Hydroscience and Engineering (ICHE), Brisbane. 